\title{
Aproximación epistemológica de la conciencia en psicología: una perspectiva comportamental
}

\author{
Edgar Salgado García ${ }^{(*)}$ \\ Universidad Latinoamericana de Ciencia y Tecnología \\ San José, Costa Rica
}

Resumen. Este ensayo presenta un panorama general acerca del estudio de la consciencia y de cómo podría conceptualizarse desde una perspectiva conductual. Se discuten las principales contribuciones del análisis experimental de la conducta y se comparan con las de los más importantes enfoques teóricos sobre la consciencia. Los primeros apartados se centran en los aspectos teóricos y empíricos relacionados con el concepto de consciencia. Los siguientes apartados versan sobre una epistemología conductual en medio de las perspectivas fenomenológica, cognoscitiva y biológica, así como algunos desarrollos en el campo del análisis de la conducta (p. ej., conducta verbal, conducta gobernada por reglas y control del estímulo), que se constituyen en alternativas a los recuentos mentalistas. Se concluye que la consciencia, desde una perspectiva comportamental, debe entenderse como conducta consciente y no como un concepto para explicar el comportamiento en sí.

Palabras clave: consciencia, conductismo, análisis conductual, psicología experimental, psicología cognoscitiva, ciencias cognoscitivas, neurociencias.

\begin{abstract}
This paper presents an overview of the study of consciousness and how it may be viewed from a behavioral standpoint. Behavior analysis' main contributions are discussed and compared with the other major approaches to consciousness. The first sections focus on the conceptual and empirical issues associated with the concept of consciousness. The next sections are devoted to discussing a behavioral epistemology in the midst of the phenomenal, cognitive, and biological perspectives, as well as some developments in the field of behavior analysis (e.g., verbal behavior, rule-governed behavior, stimulus control) that constitute an alternative to mentalistic explanations. It is concluded that consciousness, from a behavioral perspective, should be conceptualized as conscious behavior, and not as an explanatory term for behavior.
\end{abstract}

Key Words: Consciousness, behaviorism, behavior analysis, experimental psychology, cognitive psychology, cognitive science, neuroscience.

(*) Dirección postal: 3022-1000, San José, Costa Rica. Ce: esalgado@ulacit.ac.cr 


\section{Introducción}

Desde la antigüedad, los seres humanos se han preguntado sobre su lugar en el mundo. Las evidencias de que nuestros antepasados lejanos enterraban a sus muertos sugieren que estos seres "primitivos" tuvieron alguna consciencia sobre su propia naturaleza (Crick, 1994). Sin embargo, ¿podemos determinar el lugar y el momento exactos en que surgió la consciencia en la evolución de nuestra especie? Más aún, ¿de qué hablamos realmente cuando decimos que los seres humanos son conscientes? ¿Poseen otros miembros del Reino Animal este atributo que llamamos consciencia?.

Por siglos, la religión, la filosofía y más tarde, la psicología, así como otras ciencias, han intentado abordar el "enigma de la consciencia". El concepto de un alma está presente en casi todas las religiones. Se dice que un alma inmaterial, distinta del cuerpo, dicta la conducta humana. La filosofía estuvo estrechamente ligada a la tradición religiosa, tal como lo ejemplifica la explicación de Descartes sobre la relación entre mente y cuerpo (Edelman, 1992). La mente, como asiento de la razón, se equiparó con el alma, la cual caracterizaba a los humanos y los distinguía de los animales.

Cuando hablamos de consciencia, nos referimos a muchos conceptos interrelacionados. La consciencia es un concepto difícil de definir, si es que es posible del todo dar una definición (Bunge y Ardila, 1987; Chalmers, 1996). Al referirse a lo que él denomina la consciencia psicológica, Chalmers (1996) discute algunos procesos asociados con dicho concepto. Incluye así a la vigilia (la capacidad para procesar información de forma racional, lo cual puede tener lugar solamente cuando estamos alertas), la introspección (el propio conocimiento de los eventos mentales, internos), la reportabilidad (la capacidad de introspectar y de utilizar el lenguaje para reportar los propios eventos mentales), la auto-consciencia (la capacidad para distinguir el self de los otros), la atención (cuando la actividad cognoscitiva se enfoca en aspectos particulares del entorno), el control voluntario (comportarse de acuerdo con propósitos, lo cual refleja un acto de consciencia) y el conocimiento (el conocimiento de los hechos, lo cual se aproxima al uso cotidiano de la palabra consciencia).

William James concibió el pensamiento como parte de la consciencia personal (Crick, 1994). El se refirió al pensamiento como un proceso en constante cambio, sensiblemente continuo y orientado a objetos independientes. Para James, un aspecto central de la consciencia es la atención, ya que el pensamiento parece enfocarse más en ciertos objetos que en otros. Este es uno de los componentes esenciales de lo que se ha venido a denominar las "características jamesianas del pensamiento y la consciencia" (Edelman, 1992). Otra característica tiene que ver con la memoria. Crick (1994) nos refiere a un texto de Charles Richet, autor francés citado por James, quien en 1884 afirmó que la consciencia involucra las huellas que imprime sobre la mente un evento interno como el dolor.

Bunge y Ardila (1987) proponen que el problema de la consciencia tiene dos componentes: uno conceptual y otro empírico. El problema conceptual trata de la definición de la consciencia y sus procesos mentales asociados. El empírico se refiere a la generación de indicadores confiables de la consciencia. Por ejemplo, esto incluiría formas de describir cómo la consciencia se desarrolla desde la infancia y cómo cambia en función de los estímulos externos e internos. 
Por lo general, se traza una distinción entre el "darse cuenta" (awareness) y la consciencia. Chalmers (1996) argumenta que el concepto del "darse cuenta" se relaciona con la consciencia psicológica, la cual incluye una explicación funcional (causal). Afirma que el "darse cuenta" consiste en ser capaz de dirigir la conducta sobre la base de la información externa o interna. Por ejemplo, cuando reportamos verbalmente una experiencia, nos estamos "dando cuenta" de ciertos estímulos. Chalmers señala que el "darse cuenta" no necesariamente implica la capacidad de reportar los eventos, ya que los animales pueden discriminar estímulos pero no reportarlos verbalmente.

Chalmers (1996) afirma que "la consciencia está siempre acompañada por el "darse cuenta", pero el "darse cuenta", como lo he descrito, no necesita estar acompañado por la consciencia" (p.28). De forma similar, Bunge y Ardila (1987) distinguen entre el "darse cuenta" y la consciencia. Ellos sugieren que el "darse cuenta" involucra la discriminación entre estímulos (externos o internos), así como la capacidad del organismo para controlar ya sea las fuentes de estimulación o sus respuestas con respecto de esos estímulos. Su definición de consciencia incluye dos procesos: el objeto de la consciencia y el pensar sobre ese objeto. Por lo tanto, para Bunge y Ardila (1987), la consciencia consiste en pensar sobre un evento mental (una percepción, un pensamiento o un recuerdo).

El propósito del presente ensayo es el de demostrar que existe una opción alternativa a las explicaciones sobre la consciencia que hacen referencia, exclusivamente, a lo que tiene lugar dentro del organismo. Tanto los recuentos cognoscitivos como neurocientíficos de la consciencia (ahora unificados en las neurociencias cognoscitivas), así como el enfoque fenomenológico, se abocan a la estructura del organismo. Su énfasis es en cómo se comportan los organismos, pero no nos dicen por qué se comportan de determinada manera (ver Rachlin, 1994). Se debe notar que Pribram (1981) describe el enfoque conductual como un intento de tratar con las causas próximas en un sentido Aristotélico. De acuerdo con Pribram, la psicología cognoscitiva estaría también buscando las causas proximales del comportamiento en las representaciones e imágenes.

Un punto interesante, en este sentido, es la propuesta de Rachlin (1994) para estudiar el comportamiento, desde una postura molar, que contrasta con la suposición de que al análisis conductual le interesan sólo las causas proximales. El conductismo molar intentaría, entonces, explicar las causas últimas, o el por qué tiene lugar el comportamiento, a partir del estudio de las categorías de conducta a lo largo del tiempo. Otros desarrollos del análisis conductual, especialmente en las áreas del control de estímulos, la conducta verbal y la conducta gobernada por reglas, podrían ayudar también a explicar lo que podríamos llamar la conducta consciente.

Antes de presentar estos desarrollos de la ciencia de la conducta, se hará un breve recuento del estudio de la consciencia, junto con un esbozo de las cuatro principales aproximaciones, siguiendo la propuesta de Churchland (1984). Inmediatamente después, se aclararán algunos puntos de discusión importantes, tales como la distinción entre el conductismo metodológico y el conductismo radical y cómo ésta se relaciona con la manera en que el conductismo concibe la consciencia. Se discutirán algunas de las contribuciones más relevantes del análisis conductual a la comprensión de la consciencia y se establecerán comparaciones entre el enfoque conductual y los otros enfoques. 


\section{El problema de la consciencia desde diferentes perspectivas}

Como hemos visto, el concepto de la consciencia plantea un problema a la ciencia, tanto en el nivel conceptual como en el empírico. ¿Cómo podemos definir la consciencia?, ¿cuáles son las características o los componentes de la consciencia, dada la complejidad del concepto?, ¿cómo debemos proceder para estudiar la consciencia? (el problema empírico), ¿cuándo podemos decir que un organismo (humano o no-humano) es consciente?

Al distinguir entre los conceptos de consciencia psicológica y consciencia fenomenológica, Chalmers (1996) señala que el concepto psicológico no establece problemas metafísicos. Desde una explicación funcional o causal, la psicología podría estar en capacidad de explicar la consciencia en términos del "darse cuenta", el "darse cuenta del sí mismo" (self-awareness) y desde los otros aspectos que ya hemos mencionado. Sin embargo, el concepto fenomenológico es más difícil de definir y consiste en lo que se denomina el problema duro de la consciencia (Chalmers, 1997).

El concepto fenomenológico se relaciona con la forma en que percibimos las cualidades de los objetos. Estas se denominan en su conjunto, "qualia". Por ejemplo, los "qualia" se refieren a cómo percibimos "la rojeza del rojo" o "lo doloroso del dolor". Este aspecto fenomenológico o experiencial de la consciencia, de acuerdo con Chalmers (1996), es el que representa un mayor reto para los científicos.

A otros, como Crick y Koch (1997), no les interesan tanto las explicaciones fenomenológicas de la consciencia. Ellos aducen que es posible brindar una explicación científica de la consciencia. Las neurociencias podrían llegar a explicar lo que ocurre en el cerebro cuando vemos un objeto rojo o cuando sentimos dolor. Por otra parte, Chalmers (1997) cuestiona esta posición, ya que trata solamente con el problema fácil de la consciencia; es decir, los problemas de la discriminación entre estímulos, la integración de los estímulos en el cerebro, la capacidad de los seres humanos para verbalizar estados internos y cualquier otro problema asociado con los mecanismos objetivos de la cognición. Un argumento similar fue propuesto por el filósofo Thomas Nagel, autor de un ensayo en el que se pregunta "cómo se siente ser un murciélago" (Churchland, 1995). Nagel afirma que aún si las neurociencias logran descifrar las funciones de su cerebro, nadie podría saber lo que es la consciencia desde el punto de vista del murciélago.

Pareciera que un problema central al definir la consciencia es el tipo de preguntas que los científicos deberían plantear al abordar el concepto. Algunas de estas preguntas no se hacen desde la misma perspectiva. Por ejemplo, un recuento neural de la consciencia estaría siempre incompleto desde el punto de vista fenomenológico. De igual manera, los problemas metodológicos se hacen evidentes desde otra perspectiva (p. ej., la fenomenológica). ¿Cómo procederán los científicos para estudiar los "qualia”?; ¿cuáles son los signos de la experiencia interna de una persona?. Este problema se torna asimismo relevante para el neurocientífico, ya que necesitaría instrumentos altamente precisos para encontrar los correlatos neurales de la experiencia consciente (Crick, 1994). 
Aguilar (2001) ha propuesto que una aproximación al estudio de la consciencia se lleve a cabo simultáneamente desde tres "paradigmas": el fisiológico, el comportamental y el cognoscitivo. Para ello, se asume que cada paradigma posee una metodología específica.

Este autor identifica tres niveles de consciencia (instintivo, intuitivo e intelectual) que dan lugar a diferentes experiencias subjetivas o "qualias", todos los cuales podrían abordarse desde cada uno de los paradigmas mencionados. Así, por ejemplo, desde el punto de vista cognoscitivo se podría estudiar el "darse cuenta" (awareness) en el nivel instintivo, y el conocimiento simbólico en el nivel intelectual. El paradigma fisiológico daría cuenta de los niveles de consciencia, desde sus aspectos más básicos o instintivos, el tallo cerebral, hasta el más desarrollado, la neocorteza. Desde el conductual, se pasaría del estudio del reflejo (lo instintivo), pasando por la expresión facial (lo intuitivo), hasta llegar al comportamiento verbal (el nivel intelectual).

Para los científicos, el problema de la consciencia se relaciona también con los problemas que los filósofos encontraron al especular sobre él. De hecho, los filósofos contemporáneos siguen debatiendo sobre su definición. No obstante, en contraposición a las especulaciones del pasado, ahora los filósofos deben tratar con la información científica (Revonsuo, Kamppinen y Sajama, 1994). Puede que el problema de la consicencia sea además un pseudo-problema. Quizás los científicos no estén haciéndose las preguntas apropiadas. Hasta el momento, hemos considerado los puntos de vista fenomenológico y neurocientífico sobre la consciencia, pero existen igualmente otras alternativas.

\section{Los orígenes}

El estudio de la consciencia en el pensamiento Occidental, puede trazarse hasta los primeros filósofos griegos. Algunos de ellos, especialmente los llamados Pre-socráticos, asumieron una postura materialista, en el sentido de que no se refirieron a un "alma" u otra causa inmaterial de vida. El concepto de una mente separada del cuerpo fue evidente en la filosofía de Platón (sin embargo, ver Rachlin (1994) para considerar algunas interpretaciones alternativas).

Como señala Gardner (1985), la influencia de Platón continúa hasta las ciencias cognoscitivas contemporáneas. La historia de Menón, el esclavo que fue interrogado por Sócrates en torno a un problema geométrico, está todavía imbuida en las teorías representacionales de la mente (Gardner, 1985). Es como si las preguntas que los griegos se hicieran siglos atrás, continuaran sin respuesta, aunque contemos actualmente con las herramientas de la ciencia y la tecnología.

El énfasis platónico en los objetos idealizados distinguió, aparentemente, a la lógica y a la matemática como las "ciencias ideales". Aún si nos engañan nuestros sentidos, habría siempre un sentido de exactitud en la matemática. La filosofía de Descartes se fundó sobre las mismas bases. En sus Meditaciones, Descartes (1637/1971) se imaginó a sí mismo sin su cuerpo. Concluyó que si él era capaz de generar tal pensamiento, podría aún estar seguro de su existencia, ya que era él quien estaba pensándolo. Por lo tanto, la razón se convertía en parte de un ser inmaterial, el alma, que tenía una naturaleza distinta de la existencia material, o el cuerpo. Esta postura dualista permanece todavía con nosotros en gran parte de las ciencias cognoscitivas y el mentalismo. 
En el siglo XIX, la teoría de Darwin sobre la evolución comenzó a cambiar la forma en que los seres humanos se veían a sí mismos. Para Descartes, así como para casi todos los filósofos hasta el siglo antepasado, tan sólo los humanos poseían un alma. Los animales eran considerados como máquinas que respondían automáticamente a los estímulos (como en el concepto cartesiano del reflejo). La teoría evolucionista cuestionó esta postura, ya que tanto los humanos como los otros animales fueron colocados sobre un continuo. De acuerdo con Darwin (1872/1984), los humanos y los animales compartían no solamente aspectos estructurales, sino también conductuales, como la capacidad de expresar emociones.

El siglo XIX fue también testigo del surgimiento de la psicología como disciplina científica. La teoría de la vis viva, una fuerza vital que daba vida a los organismos, fue reemplazada por explicaciones mecanicistas de las funciones del sistema nervioso, principalmente con el trabajo de Herman von Helmholtz. Los psicofísicos cuestionaron la posición de Kant, según la cual la psicología no podría jamás convertirse en ciencia. Demostraron que los eventos mentales podían medirse, tal como lo hizo Donders con sus experimentos sobre cronometría mental (Posner y Raichle, 1994).

En el siglo XX, con la invención de las computadoras, los científicos empezaron a ver en esas máquinas un instrumento análogo del pensamiento humano. La revisión de Gardner (1985) sobre la historia de las ciencias cognoscitivas hace referencia a las principales influencias sobre este nuevo campo del saber. A principios del siglo XX, tuvo lugar la "revolución conductista". John B. Watson sentenció que la psicología debía concentrarse en el estudio de la conducta, no de los eventos mentales. El incipiente conductismo rechazó los términos mentalistas, incluidos, por supuesto, la mente y la consciencia.

Los recuentos contemporáneos de la consciencia son el resultado de diversas influencias, desde la filosofía, la epistemología (la filosofía de la ciencia y el conocimiento) y la psicología. Algunos de ellos se enfocan en los aspectos experienciales de la consciencia (p. ej., qué significa para el sujeto el ser consciente). Otros enfatizan los procesos de pensamiento. Estos enfoques utilizan términos como imágenes y representaciones. Otros, por su parte, se encuentran en un nivel de análisis neurofisiológico. Otros enfoques dudan de que los conceptos de imágenes o de representaciones sean necesarios y/o apropiados para dar cuenta de lo que llamamos consciencia. En los siguientes apartados, se brindará una breve descripción de cada una de las teorías más relevantes.

\section{El enfoque fenomenológico}

La fenomenología se basa en la filosofía europea, especialmente en la filosofía de Immanuel Kant. De acuerdo con Kant, el estudio de la mente no podía proceder según los métodos de las ciencias naturales, sino que debía fundamentarse en un método distinto. Ya que Kant creía que nuestra mente construye sus propias experiencias internas sobre el mundo externo. En reazón a lo anterior, la única manera de conocernos a nosotros mismos consistía en la introspección sobre nuestra naturaleza esencial (Churchland, 1984). Durante el siglo XX, la fenomenología retoma la obra de Franz Brentano y Edmund Husserl, quienes afirmaban que el método fenomenológico no 
busca causas o explicaciones, sino un análisis descriptivo, estructural, acerca de la experiencia vivida (Moss y Keen, 1981).

Por lo tanto, la aproximación fenomenológico-existencial, como se le conoce también, está interesada en la estructura de la experiencia. Como apunta Pribram (1981), "un análisis de la estructura no implica una búsqueda de las causas. La estructura tiene múltiples determinaciones y tiene muchas razones de ser" (p.146). La introspección es el método más frecuentemente utilizado por los fenomenólogos. Ellos buscan una forma de conocimiento que no esté contaminada por la "conceptualización objetivante" que sugiere la búsqueda de causas externas. En este sentido, el enfoque fenomenológico le otorga un lugar de privilegio al auto-conocimiento, por encima del conocimiento objetivo.

\section{El enfoque cognoscitivo}

Las ciencias cognoscitivas, de acuerdo con Gardner (1985), se caracterizan por: a) el uso de representaciones (p. ej., símbolos, esquemas, imágenes, ideas) para explicar el pensamiento humano; b) el uso de la computadora como modelo del pensamiento humano; c) el restar importancia al afecto, el contexto, la cultura y la historia, lo cual significa que la ciencia cognoscitiva aspira a explicaciones cognoscitivas "puras", independientes del contexto; d) el fundamento en los problemas filosóficos clásicos, como el problema de la mente y el conocimiento.

El enfoque cognoscitivo ha sido llamado también computacional, ya que propone "un sistema de estados internos gobernados por un sistema de procedimientos computacionales... El propósito es construir un esquema de la organización funcional real del sistema nervioso humano o de los sistemas nerviosos de cualquier criatura que sea objeto de estudio" (Churchland, 1984, p.92). Aunque la mayoría de los cognoscitivistas consideran que los procesos que estudian están basados en los procesos neurales, otros aseguran que el interés prioritario consiste en el programa (el "software"), no en la estructura (el "hardware"). En este caso, sería irrelevante para las ciencias cognoscitivas el que un cerebro humano o una computadora o cualquier otro órgano llevara a cabo los procesos que denominamos pensamiento.

Esta última propuesta ha sido llamada por Edelman (1992) "funcionalismo" (un funcionalismo que rehuye del contexto y la historia). Otros cognoscitivistas se acercan a los neurocientíficos, en lo que se conoce como neurociencias cognoscitivas. Sin embargo, muchos neurocientíficos no se sienten del todo a gusto con las teorías de las representaciones y las imágenes mentales (Gardner, 1985). Aún al interior de la psicología cognoscitiva, existen discrepancias en cuanto a la naturaleza de las representaciones mentales. Un recuento interesante es la propuesta de Dennett (1992), quien cuestiona el concepto de imágenes mentales.

\section{El enfoque biológico}

El materialismo metodológico postula que las actividades cognoscitivas son, en última instancia, actividades del sistema nervioso (Churchland, 1984). Un ejemplo de tal enfoque es el trabajo de Crick y Koch (1997). La bipótesis asombrosa, tal como la ha llamado Crick (1994), es la noción de que 
"usted, sus alegrías y sus penas, sus recuerdos y sus ambiciones, su sentido de identidad personal y libre albedrío, son de hecho nada más que el comportamiento de una vasta complejidad de células nerviosas" (p.3).

Desde una perspectiva evolucionista, Edelman (1992) enfatiza la importancia de una explicación histórica de la consciencia. Arguye que, para comprender el por qué somos conscientes, debemos primero entender los factores que han influido en la evolución del cerebro. Critica un recuento puramente funcionalista (cognoscitivo) sobre la consciencia, ya que no considera el contexto que ha moldeado las capacidades del cerebro humano desde el principio. Según Edelman (1992), la ciencia no podrá comprender la consciencia humana desde una perspectiva exclusivamente computacional. Por ello, los científicos deben primero indagar los orígenes de la consciencia en la historia evolutiva.

Un punto central en la teoría de Edelman es que las conexiones entre las neuronas son seleccionadas de la misma manera en que los organismos son seleccionados, siguiendo los principios de la selección natural (Edelman, 1992). Este recuento selectivo ha recibido el nombre de darwinismo neural (Edelman, 1989). El darwinismo neural es compatible con las explicaciones selectivas de la conducta. Ha venido a sustituir la posición del argumento del diseño (para una discusión más profunda del tema, ver Blumberg y Wasserman, 1995), según el cual la mente humana ha sido diseñada intencionalmente para dirigir la conducta de cierta forma. Nos encontramos, al contrario, ante una teoría basada en la selección, que enfatiza el desarrollo de la conducta (y las conexiones neurales), sobre la base de sus consecuencias adaptativas.

\section{El enfoque conductual}

Como lo ha señalado Baum (1994), el primer conductismo (el conductismo metodológico) estaba demasiado preocupado por la distinción entre lo objetivo y lo subjetivo. Basados en la filosofía del realismo, los conductistas metodológicos intentaron explicar la conducta en términos de lo estrictamente observable. La introspección fue rechazada como método de indagación psicológica. Los términos mentalistas fueron desterrados.

El problema del conductismo metodológico fue el no haber ni siquiera intentado estudiar los eventos privados, bajo el supuesto de que éstos eran “subjetivos". El positivismo lógico, que establecía que todo término científico debía corresponder a nociones observacionales, ejerció una influencia importante sobre el conductismo metodológico (Churchland, 1984).

Por otra parte, el conductismo radical sí se propuso explicar los eventos privados. No se basó en el realismo, sino en el pragmatismo, que consideraba legítimos los conceptos y las explicaciones útiles para comprender los fenómenos de la naturaleza (Baum, 1994). Sin embargo, estos eventos privados no fueron considerados como causas del comportamiento. Como afirma Holland (1981), "B.F. Skinner incluye en su propio ámbito de investigación a los sentimientos, los pensamientos, las imágenes y la consciencia. Es cierto, él no considera que éstos sean conceptos explicativos, sino

eventos legítimos como objetos de estudio" (p.97). En su libro "Sobre el Conductismo", Skinner (1974) escribió: 
Se podría decir del conductismo metodológico y ciertas versiones del positivismo lógico que ignoraron la consciencia, los sentimientos y los estados mentales, pero el conductismo radical no "le corta la cabeza" al organismo; no intenta "barrer debajo de la alfombra" el problema de la subjetividad; no "mantiene una metodología estrictamente conductista al tratar los reportes de la introspección meramente como conducta verbal"; y no fue concebida para "permitir que la consciencia se atrofie" (p.219).

\section{Un análisis comportamental de la consciencia}

Las explicaciones comportamentales de la consciencia se oponen al mentalismo. Tal como apunta Hocutt (1996), el conductismo contrasta con lo que él llama cartesianismo. Dentro del marco cartesiano, los seres humanos no interactuamos directamente con el mundo externo, sino con nuestras ideas o representaciones sobre el mundo. El cartesianismo también engloba a las doctrinas del innatismo (las ideas son innatas), el dualismo (la distinción mente-cuerpo), el racionalismo (el pensamiento consiste en razonamiento lógico), así como la noción de una mente exclusivamente humana.

El análisis conductual, basado en los principios de la selección filogenética y ontogenética, conceptualiza la consciencia como un comportamiento moldeado por la historia evolutiva y de aprendizaje. Los eventos privados, al igual que los públicos, son todos parte del mundo natural y, por lo tanto, se encuentran sujetos al escrutinio científico (Ardila, 1993). En otras palabras, el análisis conductual cuestiona la visión cartesiana de que la mente y el cuerpo responden a naturalezas distintas.

Las preocupación del conductismo metodológico con el realismo fue sustituida por el pragmatismo del análisis conductual. La naturaleza del realismo como alternativa epistemológica ha sido discutida por Maturana y Varela (1992) en términos de "certeza". Los seres humanos constantemente buscamos lo que es certero (real), pero como estos autores lo proponen, nuestra respuesta a los colores no depende de las longitudes de onda (un atributo de los estímulos), sino de nuestra historia de aprendizaje. Lo mismo puede decirse de los estímulos verbales. Los significados no están en las palabras, sino en nuestras respuestas ante las palabras (Catania, 1998). A esto hay que agregarle que el contexto en que se emiten las palabras determina también el significado, tal como se ha estudiado desde el paradigma de la discriminación condicional.

Por lo tanto, un punto de partida para entender la consciencia desde una perspectiva comportamental reside en definir su epistemología; es decir, su teoría implícita sobre el conocimiento. Esta epistemología no niega la existencia de un mundo externo, ya que los organismos evolucionaron para adaptarse a las contingencias ambientales. No obstante, no se adhiere a la idea de un organismo que responde mecánicamente ante un mundo objetivo, totalmente independiente de su experiencia. En este sentido, Maturana y Varela (1992) consideran que el conocimiento (incluyendo el auto-conocimiento) es acción. El análisis conductual comparte también esta posición, ya que tanto el auto-conocimiento, como el "darse cuenta", han sido concebidos como conductas. 
Desde lo comportamental, el problema de la consciencia se relaciona con los contextos en los cuales decimos que un organismo es consciente. El significado más simple de la palabra consciencia consiste en percatarse del ambiente. Decimos que una persona está consciente cuando responde a los estímulos ambientales. Por otro lado, decimos que alguien está inconsciente cuando la persona no responde a los estímulos externos (Holland, 1981). Aún así, puede no ser suficiente decir que el ser consciente implica la sola capacidad del organismo para responder ante su ambiente. Por ejemplo, según Baum (1994), decimos que una persona "sabe o conoce algo" (y en este caso diríamos que la persona es "consciente de algo"), cuando se comporta de forma adecuada al contexto (p. ej., emite una conducta que es reforzada en presencia de estímulos discriminativos correlacionados). Por lo general, consideramos que una persona está consciente de sus acciones cuando es capaz de verbalizar las contingencias que controlan su comportamiento.

\section{La consciencia como producto social}

En el tanto que la conducta verbal es moldeada por una comunidad verbal, nuestras descripciones verbales de nuestros propios estados mentales (lo que podríamos denominar "autoconocimiento"), son en sí un producto social (Ardila, 1993). La comunidad verbal enseña a los individuos a discriminar sus estímulos internos a través de los correlatos públicos de los eventos privados (Poling, Schlinger, Starin, y Blakely, 1990). El lenguaje de los eventos privados (emociones, sentimientos, tendencias) está moldeado por el contexto social. Esto significa que el problema de la consciencia no es un problema estrictamente individual, que pueda resolverse indagando en el mundo interno de la persona, sino que involucra el contexto en el que la persona actúa.

El reporte de eventos privados reviste una importancia social. Por ejemplo, una persona que reporta sentirse triste, obtiene la ayuda y atención de los demás. La capacidad para identificar si una persona está enojada ayuda a los otros a evitar ser atacados. El problema de las descripciones de los eventos privados consiste en que, al reforzar las respuestas de los demás, no tenemos acceso al estímulo privado que experimenta el otro. Debemos basarnos únicamente en los eventos públicos (las conductas observables) que acompañan a los eventos privados (Baum, 1994; Poling et al., 1990).

Sin embargo, el problema de la consciencia tampoco se reduce a la cuestión del reporte de los eventos privados. Afirmamos que una persona es consciente de un estímulo (o de una propiedad específica de un estímulo), cuando esa persona responde no sólo verbalmente, sino también de forma no verbal en presencia del estímulo. Por ejemplo, decimos que una persona está consciente de una señal de alto cuando pisa el pedal del freno al ver la señal. De igual forma, decimos que alguien es consciente de un objeto, cuando reporta una conducta observacional (ver o escuchar) con respecto de ese objeto. Skinner (1974) se refirió a este fenómeno en términos de "ver que estamos viendo".

Por ejemplo, una persona mira un cuadro y dice: "estoy viendo el árbol verde que está hacia la izquierda". Enseguida decimos que la persona se percata de ese objeto específico en el cuadro (ver Poling et al., 1990, quienes ofrecen un ejemplo similar). Estas discriminaciones se enseñan a partir 
del reforzamiento diferencial. Al establecer contacto con las características del ambiente, tanto el que habla como el que escucha tienen acceso a los estímulos (y en este caso los estímulos son eventos públicos), de forma que el reforzamiento diferencial se torna más preciso. Eventualmente, la conducta verbal deviene en mayor complejidad, hasta que la persona es capaz de hablar sobre su propia conducta verbal. Este último fenómeno se denomina "conducta verbal autoclítica" (Catania, 1998).

\section{La conducta verbal y la consciencia}

La conducta autoclítica consiste en discriminar nuestra propia conducta verbal. Emitimos conducta verbal que se encuentra bajo el control de nuestra conducta verbal previa. Por ejemplo, podríamos construir sobre otras operantes verbales primarias (como los "tactos") y reportar que estamos seguros de algo, que dudamos algo o que vemos que algo está sucediendo. Con respecto de la conducta autoclítica, Catania (1998) afirma que:

Los autoclíticos descriptivos demuestran que el análisis de la conducta verbal es un asunto de comportamiento y no de lógica. Decir "Esto es asî" o "Esto es probable" o "No puede ser" es conducta verbal con respecto de otra conducta verbal. Reducir tales oraciones a la lógica simbólica o a la matemática de la probabilidad podría resultar útil para solucionar problemas, pero dicha reducción elimina una característica central del lenguaje humano. Las discriminaciones de la propia conducta son un prerrequisito para lo que llamamos consciencia o "darse cuenta"; los autoclíticos descriptivos sugieren que esos fenómenos están relacionados de forma singular con las propiedades del lenguaje humano (p.247).

Hay dos problemas importantes en la cita anterior. Primero, el autor afirma que la conducta autoclítica, como una clase de conducta verbal que puede caracterizarse como "hablar sobre el hablar", no puede comprenderse si ignoramos el contexto de dicha conducta (nuestra propia conducta verbal que la controla, así como las circunstancias en la cual tiene lugar). Tratar a la conducta verbal como un asunto puramente lógico, como lo han hecho los teóricos cognoscitivistas, deja por fuera un atributo esencial de la conducta verbal. Segundo, la capacidad para "hablar sobre el hablar" distingue a los seres humanos de los otros miembros del reino animal. No obstante, existen estudios en los que se ha encontrado que los animales son capaces de discriminar aspectos de su propia conducta (ver Pérez-Acosta, Benjumea, y Navarro (2001a).

Jaynes (1976), en una amplia discusión del concepto de la consciencia y sus orígenes, sugiere algo similar sobre la relación entre la conducta verbal y la consciencia. Afirma que el concepto de consciencia es en sí mismo una metáfora, una creación de nuestra propia conducta verbal. Los seres humanos intentan hacer comprensibles los fenómenos naturales mediante el uso de la metáfora. En las metáforas, utilizamos la conducta verbal para describir eventos cotidianos y extendemos tales descripciones a otros fenómenos más complejos.

La ciencia utiliza la metáfora para comprender las relaciones entre los eventos naturales (ver Baum, 1994, para una descripción de cómo el pragmatismo utiliza explicaciones que "tienen 
sentido"). Por lo tanto, el lenguaje hace posible el concebir a "algo" llamado consciencia. Como punto interesante, Jaynes (1976) propone que la mayoría de nuestro comportamiento no necesita de la consciencia. La consciencia emerge cuando hablamos sobre nuestra propia conducta verbal. Desde esta postura, la reactividad (el responder a los estímulos) no siempre implica a la consciencia. Más aún, si estuviésemos siempre conscientes de cada aspecto de nuestro comportamiento, la ejecución de conductas complejas, como por ejemplo tocar el piano, se nos dificultaría significativamente (Jaynes, 1976).

Queda aún una pregunta, que consiste en si podríamos decir que un organismo está consciente si no muestra signos (conductas observables) de estar consciente. Por ejemplo, una persona que se encuentre paralizada, sin poder hablar, podría percibir estímulos y "construir experiencias propias". Esta persona podría estar percibiendo y atendiendo a los estímulos del ambiente, pero no podría reportar sus experiencias. Aún cuando estamos despiertos y ejerciendo control sobre nuestros actos, no siempre verbalizamos los eventos (tanto públicos como privados) que controlan nuestro comportamiento (Ardila, 1993).

Muy probablemente, el tipo de eventos que no podemos verbalizar se relaciona con la conducta moldeada por las contingencias (Baum, 1994). Muchas respuestas son aprendidas de esta forma, como cuando montamos una bicicleta o tocamos un instrumento musical. No podemos poner en palabras los eventos que controlan nuestra conducta de montar en bicicleta. Pareciera, simplemente, que esta conducta se exhibe de forma automática. Como se ejemplificó anteriormente, si el pianista pudiese estar consciente de cada pulsación de las teclas durante un concierto, probablemente no podría tocar bien.

Pasando a otro tipo diferente de conducta, en el ámbito del comportamiento anormal, lo que se ha denominado "comportamiento neurótico" surge de contingencias que las personas no son capaces de verbalizar. Esta es una de las observaciones que, probablemente, hizo que Sigmund Freud postulara el concepto de inconsciente. El papel del psicoanalista consistía en ayudar a la persona a "hacer consciente lo inconsciente". Desde una perspectiva conductual, podríamos decir que el terapeuta ayuda al paciente a identificar las contingencias (la relación entre la conducta de la persona y sus antecedentes y consecuencias) que han promovido la conducta problemática. Entonces, por medio de la conducta autoclítica, la persona desarrolla la capacidad de describir dichas contingencias (aprende a discriminar su propia conducta, tanto verbal como no verbal).

La distinción entre conducta moldeada por las contingencias y conducta gobernada por reglas (Skinner, 1974), es pertinente para el problema del auto-conocimiento y el "darse cuenta", en varios aspectos importantes. La conducta gobernada por reglas se relaciona con el "saber acerca de", mientras que la conducta que es moldeada por las contingencias se relaciona con el "saber cómo" (Baum, 1994). Cuando nos comportamos de acuerdo con un contexto, "sabemos acerca de algo". El saber sobre el mundo externo, así como el saber acerca de nuestros eventos privados, se produce a partir del reforzamiento diferencial en presencia de diferentes contextos. Cuando una persona se comporta apropiadamente al contexto, nos inclinamos a decir que la persona está consciente de sus acciones. Cuando una persona emite una conducta inapropiada (p. el., un comportamiento anormal, neurótico o psicótico) relativa a aun contexto, tendemos a decir que la persona podría no estar 
consciente de sus actos. Las reglas son verbalizadas con mayor facilidad, ya que consisten en proposiciones verbales sobre las contingencias. Por lo general, las reglas se establecen de forma explícita e incluso, en algunas ocasiones, pueden tener preponderancia sobre las contingencias (Catania, 1998). No obstante, una persona podría o no estar en capacidad de verbalizar la contingencia última a la que hace referencia la regla.

En general, en análisis conductual contribuye al estudio de la consciencia de diferentes formas. En primera instancia, enfatiza una explicación histórica sobre la consciencia. Las contingencias filogenéticas, ontogenéticas y culturales han moldeado nuestro comportamiento hasta convertirlo en un fenómeno complejo, que concebimos bajo el concepto de consciencia. En segundo lugar, enfatiza el lenguaje, especialmente el papel de las discriminaciones sobre nuestro propio comportamiento y la utilización de los "tactos extensos" (metáforas) como un aspecto esencial de la consciencia y la vigilia. En tercer lugar, propone conceptos como la conducta gobernada por reglas y moldeada por las contingencias, que nos ayudan a distinguir entre lo consciente (aquello que puede ser verbalizado) y lo inconsciente (lo que no se puede verbalizar). Un tema común surge de estos aspectos, siendo éste quizás el aporte más relevante del análisis conductual: el estudio del contexto en que tiene lugar el comportamiento.

\section{Estudios sobre autodiscriminación condicional y relaciones de equivalencia}

Los estudios recientes de análisis experimental de la conducta se han centrado en la capacidad de los seres humanos (y los animales también) de discriminara aspectos de su propia conducta. Pérez-Acosta, Benjumea y Navarro (2001b) han propuesto que el paradigma de la discriminación condicional, propio del análisis conductual, puede servir de base para comprender la capacidad de autoconsciencia, la cual definen como “...una extensión del control de estímulos en la cual el discriminativo es algún aspecto del mismo individuo que se comporta” (p.9).

De acuerdo con el paradigma de la autodiscriminación condicional, el individuo aprendería, por medio del reforzamiento social, a asociar etiquetas verbales a los estados internos. Por ejemplo, al estar presente un estado interno determinado, la persona emitiría la respuesta "estoy preocupado" o "estoy contento", la cual sería moldeada socialmente. En este caso, el estímulo discriminativo condicional sería el estado interno.

Otro paradigma que está recibiendo mucha atención actualmente en análisis experimental es el de las relaciones de equivalencia. En una revisión sobre los conceptos analítico-conductuales sobre la autoconciencia, Dymond y Barnes (1997) abordan esta temática en profundidad, por lo que se refiere al lector a dicho trabajo.

En las relaciones de equivalencia, surgen relaciones entre estímulos de forma espontánea, sin que a los sujetos se les haya entrenado explícitamente. Las relaciones de equivalencia se manifiestan siguiendo los principios de reflexividad, simetría y transitividad (como en las matemáticas). En el ser humano, dichas relaciones toman formas muy complejas. Recientemente, se habla de una teoría de los "marcos relacionales" (ver Dymond y Barnes, 1997), en donde las relaciones arbitrarias y espontáneas entre los estímulos (relaciones de equivalencia) se desligan de la historia de 
reforzamiento del sujeto. Esta nueva perspectiva aporta elementos cruciales para comprender la autoconsciencia en los seres humanos.

\section{La perspectiva conductual y las otras perspectivas}

De acuerdo con Hocutt (1996), los cartesianistas modernos o mentalistas no comparten el recuento funcionalista de la consciencia. Los metalistas arguyen que hay siempre un vacío, una experiencia interna que es dejada de lado por el análisis funcional. La noción de la consciencia como un "teatro" o un "espacio" en el cual tienen lugar los eventos ha sido común en muchas de las teorías (cartesianas) sobre la consciencia(Jaynes, 1976; ver también Rachlin, 1991, para una discusión del dualismo cartesiano). Surgen así algunas preguntas, tales como: ¿dónde está el asiento de la consciencia?, ¿de qué se componen las ideas, imágenes y sentimientos que desfilan por el “Teatro Cartesiano”?, ¿son diferentes de los objetos tangibles?.

Si consideramos la consciencia como un producto social, íntimamente ligado con el comportamiento verbal, realmente no necesitamos caer en la trampa del cartesianismo. La ciencia trata con el dominio de los eventos naturales. ¿Cómo puede algo no natural causar un evento natural, como el moverse o el hablar?. La ciencia cognoscitiva "pura" intenta comprender la cognición humana en términos de procesos lógicos, independientes del contexto(Gardner, 1985). Como sugiere Catania (1998), tal enfoque falla al explicar por qué una persona puede decir algo en un contexto y algo diferente en otro contexto. Si el lenguaje está conectado con el concepto de consciencia, entonces una explicación de la consciencia debería también incluir el contexto en el cual se desarrolla en comportamiento verbal.

A propósito, recientemente el análisis experimental de la conducta ha comenzado a estudiar fenómenos antes reservados a los científicos cognoscitivistas. Por ejemplo, la investigación cognoscitiva en psicolingüística ha demostrado que las personas recuerdan la estructura profunda del lenguaje con mayor facilidad que la estructura superficial (Baars, 1986). Ya que el análisis conductual trata con clases de conducta funcionales más que estructurales, estos hallazgos son compatibles con los recuentos conductuales sobre el lenguaje.

No aprendemos una estructura fija de una oración. Con mayor probabilidad, responderemos a una clase funcional de conducta verbal, cuyos miembros producen, todos ellos, el mismo efecto sobre quien escucha (Morgan y Buskist, 1990). Es posible que el lenguaje (las metáforas que cada uno utiliza) de los cognoscitivistas y de los conductistas sean asimismo un ejemplo de estructuras superficiales. Quizás las estructuras profundas que subyacen sus hallazgos sean más similares entre sí de lo que pensábamos. Sin embargo, la diferencia en la forma en cómo hablan de su propia conducta (o sus procesos cognoscitivos) es lo que ha dificultado el diálogo entre los dos enfoques (Catania, 1998).

La aproximación fenomenológica plantea un reto aún mayor para explicar la consciencia desde un punto de vista funcionalista. El problema es que los fenomenólogos no se darán por satisfechos hasta tanto se construya una teoría de la experiencia consciente o los "qualia". Considérese la siguiente cita de Garrett (1996): 
Los extraterrestres (llámense "Zebs") se aprestan a estudiar a los humanos. Imaginemos que los Zebs nunca sienten dolor. Además, los Zebs son teóricos del reforzamiento... Asumamos que ellos son aún más hábiles que nosotros para predecir y controlar nuestra conducta de dolor. En ese caso, retomando la noción de Skinner sobre lo que es una explicación, debemos decir que ellos comprenden nuestra conducta de dolor mejor que nosotros mismos. Pero ellos no tienen ni la menor pista sobre lo que significa el sentir el dolor, aunque nosotros sí. Y, además, nosotros sabemos (pero ellos no lo pueden saber) que si no fuese por el sentimiento de dolor, nuestra conducta sería muy diferente de lo que es. Propongo, entonces, que es debido precisamente a que los Zebs no tienen el menor entendimiento del papel crucial que juega el dolor en nuestro comportamiento, que ellos no comprenden a cabalidad nuestra conducta (p.143).

Si definimos el problema de la consciencia en términos de la consciencia fenomenológica (Chalmers, 1996), un recuento conductual siempre se quedaría corto. No obstante, el problema de la consciencia fenomenológica puede verse también desde otra óptica. Como propone Rachlin (1991), a menos que podamos entrar en el cuerpo de otra persona, la única manera que tenemos de saber que alguien tiene, por ejemplo, un dolor en la pierna, es por observación, a lo largo de un período de tiempo, que la persona emite ciertas conductas que pertenecen a la categoría "dolor en la pierna". La categoría de "dolor en la pierna" incluye muchas instancias conductuales, como el quejarse, caminar de cierta manera y otras.

En su libro Behavior and Mind (Conducta y Mente), Rachlin (1994) discute un punto similar, pero referido a la categoría de "amor". Plantea que si él amara a una mujer durante toda su vida y justo cuando ella estuviese muriendo le dijera a él que ella es realmente un robot y no un ser humano, él siempre sufriría al perderla. ¿Significa eso que Rachlin no comprendía el amor, sólo porque nunca pudo haber sabido lo que el robot estaba sintiendo?.

La fenomenología enfatiza el auto-conocimiento sobre el conocimiento objetivo. De acuerdo con esta visión, nos conocemos a nosotros mismos mejor de lo que conocemos a los otros. Nuestro conocimiento propio es "de primera mano", no se encuentra "contaminado" por los eventos externos. Pero como señala Nye (1992), si no fuese por nuestra comunidad verbal, el autoconocimiento no existiría del todo. El argumento de los fenomenólogos es que los "qualia" son un tipo especial de entidad interna, conocida sólo por la persona que la experimenta. Mas la dificultad para explicar la naturaleza de los "qualia" refuerza la noción conductista de que no podemos conocer lo que ocurre dentro de nosotros tan bien como conocemos el mundo externo (Nye, 1992). Quizás el problema de la consciencia solamente podrá resolverse de forma incompleta. Tal vez no lleguemos a ser capaces de saber "qué se siente ser un murciélago" (u otra persona), pero un recuento funcional es posible (Rachlin, 1994). Un recuento científico también es posible desde un nivel neurofisiológico, aunque éste se centraría en eventos internos (fisiológicos, no mentales o experienciales) (Crick, 1994).

Con respecto de las explicaciones neurales de la consciencia, existe todavía mucho terreno que cubrir. Una pregunta esencial es si un recuento neural podría reemplazar un análisis comportamental de la consciencia. En su ensayo Behaviorism at Fifty (El Conductismo a los Cincuenta), Skinner (1963) hizo un importante comentario en este sentido. Dijo que aún si la 
neurofisiología pudiese explicar el comportamiento humano, las personas seguirían comportándose en un contexto y éste sería siempre del dominio del análisis conductual. Un ejemplo para clarificar este punto consistiría en preguntarnos si comprendemos un reloj mediante el conocimiento de su mecanismo interno. Podríamos llegar a comprender cómo funciona, pero podríamos no comprender por qué alguien construiría un aparato tal. ¿Qué función cumple?, ¿por qué existe ese mecanismo?. Necesitamos explicaciones históricas y, muy probablemente, éstas deberían incluir explicaciones sobre las contingencias que motivaron a los seres humanos a construir un mecanismo para llevar la cuenta del tiempo.

Desde un punto de vista neurobiológico, el argumento de Edelman (1992) hace igualmente un llamado a un recuento histórico. De nuevo, necesitamos una explicación histórica, ya que aún si descifráramos cómo funciona el cerebro, quedaría la pregunta sobre cómo el cerebro humano llegó a tener sus capacidades singulares. Las contingencias filogenéticas jugaron un papel en su evolución. Las contingencias selectivas ontogenéticas moldean las diferencias individuales. Millones de neuronas son desechadas desde el nacimiento y sólo las conexiones (sinapsis) más fuertes se conservan durante el desarrollo.

Donahoe (1996) sugirió que el principio de selección debería ser estudiado tanto por las ciencias biológicas como las sociales. Este autor enfatiza que la selección en las redes neurales no debería inferirse a partir de observaciones conductuales, sino que tiene que demostrarse en un nivel apropiado (el nivel neurofisiológico). Parece que la hipótesis de Edelman (1992) está empezando a hacer precisamente eso. Una relación importante entre el análisis conductual y la neurofisiología está en el aporte del primero para entender cómo y por qué se comportan los organismos, de forma que el segundo pueda abocarse a la investigación de lo que ocurre al nivel neural.

\section{Conclusiones}

En la más importante publicación científica de investigación conductual básica, el Journal of the Experimental Analysis of Behavior (Revista de Análisis Experimental del Comportamiento), es posible encontrar solamente unos pocos artículos cuyas Palabras Clave incluyen el concepto de consciencia. Casi todos ellos se relacionan con la reciente teoría de la asignación de nombres (naming theory) de Horne y Lowe (1996). ¿Cómo es, entonces, que el análisis conductual aborda empíricamente el problema de la consciencia?. Es cierto que la consciencia, como ficción explicativa, no tiene lugar en un recuento científico sobre el comportamiento, pero la tarea persiste en cuanto a brindar una explicación alternativa para las clases de conductas que consideramos conscientes. Como hemos visto a lo largo de los apartados anteriores, la palabra "consciencia" tiene diferentes significados (es utilizada en diferentes contextos), de acuerdo con las diferentes tradiciones filosóficas y científicas.

Sin embargo, el análisis conductual sí ofrece los cimientos para una explicación científica de la consciencia. Se debe considerar que el análisis conductual es una ciencia independiente, separada de la biología (Donahoe, 1996). El análisis conductual puede concebirse como una ciencia "limítrofe", en el medio de los niveles biológico y cultural (Glenn, 1988). Las principales contribuciones del 
análisis conductual al estudio de la consciencia parecen derivarse del análisis de la conducta verbal, el control de estímulos y el auto-conocimiento (Baum, 1994). Desde un punto de vista epistemológico, el análisis conductual contribuye también al proveer una visión no mentalista y sí contextualista de los fenómenos del comportamiento humano.

El análisis conductual contempla igualmente la posibilidad de una explicación histórica del comportamiento consciente, tanto desde una perspectiva filogenética como ontogenética. Las relaciones entre la selección natural y la selección ontogenética constituyen un continuo a partir del cual podemos comprender la evolución del comportamiento consciente. La consciencia, en nuestra especie, evolucionó no sólo en función de las exigencias ambientales, sino también como producto de las contingencias creadas por nosotros mismos. Así, las metacontingencias culturales son esenciales para comprender el comportamiento humano (Glenn, 1988). Ya que un aspecto fundamental del comportamiento consciente es el resultado de contingencias socioculturales, el análisis conductual contribuye a la comprensión de los aspectos antropológicos de la consciencia. Como ejemplo de este último aspecto, se ha estudiado cómo diferentes culturas muestran una consciencia mayor de algunos aspectos del ambiente físico en el que viven. Glenn (1988) ha propuesto una síntesis del materialismo cultural (una perspectiva antropológica) y el análisis conductual, capaz de dar cuenta de las diferentes manifestaciones interculturales del comportamiento consciente.

En cuanto a los aspectos ontogenéticos del comportamiento consciente, la teoría molar de Rachlin (1994) tiene mucho que aportar a un análisis comportamental de la consciencia. Desde su perspectiva, los conceptos mentales pueden comprenderse haciendo referencia a patrones de conducta extendidos en el tiempo, en la forma de categorías de conducta. Una propuesta similar puede encontrarse en el trabajo de Gilbert Ryle (citado por Baum, 1997). En este sentido, Rachlin plantea una alternativa a "las explicaciones de la conducta como un evento momentáneo dirigido por causas previas" (Baum, 1997, p.13). Esta postura se relaciona también con la psicología interconductual de J.R. Kantor (Moore, 1984). Aunque no se discutió a profundidad en el presente ensayo, la filosofía de Kantor ha tenido un influjo importante en el trabajo de Rachlin, ya que se basa, entre otros aspectos, sobre los principios del naturalismo (el rechazo del mentalismo y las causas sobrenaturales del comportamiento) y de la causalidad múltiple (el comportamiento no puede ser explicado adecuadamente haciendo referencia a una sola causa).

Al principio de este artículo se hizo referencia a las causas próximas y últimas del comportamiento. Se comentó la opinión de algunos autores que consideran que el análisis conductual trabaja únicamente con las causas próximas. La teoría de Rachlin propone justo lo contrario: un recuento científico del comportamiento basado en las causas últimas. Esto supone una observación sistemática de la conducta a lo largo del tiempo. Siguiendo la revisión de Baum (1997) sobre el libro de Rachlin titulado Conducta y Mente:

Quizás el aspecto más interesante del enfoque de Rachlin consiste en su propuesta de tratar los términos mentales como patrones extendidos (en el tiempo) de comportamiento observable (público). Como en la sensación visual, la 
percepción o el dolor, él afirma que, en general, amar, esperar, creer o intentar significa exhibir suficientes instancias de un patrón para inducir tal juicio en un observador (ya sea alguien más o uno mismo) (p.15).

Por lo tanto, de acuerdo con Rachlin (1994), los términos "duros" como la sensación, la percepción e incluso el dolor, los cuales establecen la problemática de los "qualia", podrían entenderse en términos de patrones extendidos de comportamiento. Esta perspectiva cobra relevancia como una alternativa a las aproximaciones fenomenológicas que se expusieron anteriormente.

Otro concepto importante para la investigación futura sobre el comportamiento consciente es la sintesis conductual (Catania, 1998). Este concepto se refiere a que, si el análisis conductual posee las herramientas conceptuales y metodológicas para abordar científicamente el tema de la consciencia, entonces debería estar en condiciones de diseñar experimentos para estudiar las contingencias específicas asociadas con esta clase de conducta.

Por ejemplo, la discusión contemporánea sobre las relaciones de equivalencia y la naming theory (Horne y Lowe, 1996), podría generar estudios sobre cómo se desarrollan las habilidades del lenguaje en los niños. La asignación de nombres (naming) parece estar relacionada con la consciencia, ya que se basa en la formación de clases supraordinales de conducta simbólica. Esto podría ayudar a explicar cómo se desarrollan, a lo largo del ciclo de vida, las habilidades lingüísticas para asignar nombres tanto a los objetos externos, como a eventos internos, sentándose así las bases para una historia ontogenética del comportamiento consciente.

A partir de la investigación experimental se podría abordar también el problema de la consciencia en los animales. Aunque no fue objeto de este ensayo, se debe dejar claro que, desde una perspectiva conductual, no se puede trazar una línea divisoria definitiva entre la consciencia humana y la no humana. La investigación desde el análisis experimental del comportamiento contribuirá a su vez a establecer las similitudes, así como las diferencias existentes en este sentido. En este sentido, el paradigma de la autodiscriminación condicional seguirá generando estudios con humanos y animales que ayudarán a comprender mejor las posibilidades de las especies no humanas, así como los atributos exclusivos de la consciencia humana.

Como reflexión final, surge una pregunta sugestiva: ¿tiene el concepto de consciencia, después de todo, un lugar dentro del análisis conductual?. Si este término es utilizado como una explicación general del comportamiento, entonces nuestra posición es que no debería utilizarse. Si decimos que una persona puede verbalizar una experiencia y explicamos su conducta como resultado de su "ser consciente", no hay allí una verdadera explicación en nuestro argumento. Quizás una mejor forma de referirnos a la consciencia, desde la perspectiva comportamental, sea utilizar el término que aquí hemos adoptado, "comportamiento consciente". Así, los analistas conductuales podrían abordar la consciencia desde su enfoque particular, sin rechazar de todo el concepto, como sí lo hicieron los primeros conductistas metodológicos.

El análisis conductual tiene todavía un largo camino que recorrer en lo que se refiere al estudio del comportamiento consciente. Queda todavía mucho trabajo que hacer, no sólo desde lo empírico, sino también desde lo conceptual. Hemos considerado aquí solamente algunas 
contribuciones que podrían alentar una mayor investigación que enriquezca nuestra comprensión teórica del comportamiento consciente.

\section{Referencias}

Aguilar, A. (2001). Cómo estudiar la consciencia: tres paradigmas para la psicología. Revista Latinoamericana de Psicología, 33, 11-21.

Ardila, R. (1993). La sintesis experimental del comportamiento: Hacia una psicología unificada. Bogotá: Planeta.

Baars, B.J. (1986). The cognitive revolution in psychology. New York: The Guilford Press.

Baum, W.M. (1994). Understanding behaviorism: Science, behavior, and culture. New York: Harper Collins.

Baum, W.M. (1997). New paradigm for behavior analysis: A review of Behavior and Mind by Howard Rachlin. The Behavior Analyst, 20, 11-15.

Blumberg, M.S. \& Wasserman, E.A. (1995). Animal mind and the argument from design. American Psychologist, 50, 133-144.

Bunge, M. \& Ardila, R. (1987). Philosophy of psychology. New York: Springer-Verlag.

Catania, A.C. (1998). Learning. Englewood Cliffs, New Jersey: Prentice-Hall.

Chalmers, D.J. (1996). The conscious mind: In search of a fundamental theory. New York: Oxford University Press.

Chalmers, D.J. (1997 Special Issue). The puzzle of conscious experience. Scientific American, 30-37.

Churchland, P.M. (1984). Matter and consciousness: A contemporary introduction to the philosophy of mind. Cambridge: MIT Press.

Churchland, P.M. (1995). The engine of reason, the seat of the soul: A philosophical journey into the brain. Cambridge: MIT Press.

Crick, F.H.C. (1994). The astonishing hypothesis: The scientific search for the soul. New York: Charles Scribner's Sons.

Crick, F.H.C. \& Koch, C. (1997 Special Issue). The problem of consciousness. Scientific American, 18-26.

Darwin, C. (1984). La expresión de las emociones en los animales y en el hombre. Madrid: Alianza Editorial.

Dennett, D. (1992). The nature of images and the introspective trap. En B. Beakley \& P. Ludlow (Eds.), The philosophy of mind: Classical problems/contemporary issues (pp.212-216). Cambridge: MIT Press.

Descartes (1971). Discourse on method. En E. Anscombe \& P.T. Geach (Eds.), Descartes' philosophical writings. (pp.5-58). Indianapolis: Bobbs-Merrill.

Donahoe, J.W. (1996). On the relation between behavior analysis and biology. The Behavior Analyst, 19, 71-73.

Dymond, S. \& Barnes, D. (1997). Behavior-analytic approaches to self-awareness. Psychological Record, 47, 181 200.

Edelman, G.M. (1989). The remembered present: A biological theory of consciousness. New York: Basic Books.

Edelman, G.M. (1992). Bright air, brilliant fire: On the matter of the mind. New York: Basic Books.

Gardner, H. (1985). The mind's new science: A bistory of the cognitive revolution. New York: Basic Books.

Garrett (1996). Skinner's case for radical behaviorism. En W.O. O’Donohue \& R.F. Kitchener (Eds.), The philosophy of psychology (pp.141-148). Thousand Oaks: Sage Publications.

Glenn, S.S. (1988). Contingencies and metacontingencies: Toward a synthesis of behavior analysis and cultural materialism. The Behavior Analyst, 11, 161-179. 
Hocutt, M. (1996). Behaviorism as opposition to Cartesianism. En W.O. O'Donohue y R.F Kitchener (Eds.), The philosophy of psychology (pp.81-95). Thousand Oaks: Sage Publications.

Holland, J.G. (1981). Radical behaviorism and consciousness. En R.S. Valle \& R. von Eckartsberg (Eds.), The metaphors of consciousness (pp.97-106). New York: Plenum Press.

Horne, P.J. \& Lowe, C.F. (1996). On the origins of naming and other symbolic behavior. Journal of the Experimental Analysis of Behavior, 65, 185-241.

Jaynes, J. (1976). The origins of consciousness in the breakdown of the bicameral mind. Boston: Houghton Mifflin Company.

Maturana, H.R. \& Varela, F.J. (1992). The tree of knowledge: The biological roots of human understanding. Boston: Shambhala.

Moore, J. (1984). Conceptual contributions of Kantor's interbehavioral psychology. The Behavior Analyst, 7 , 183-187.

Morgan, D.L. \& Buskist, W. (1990). Conversations with the keepers of the internal order: A review of B.J. Baars' The Cognitive Revolution in Psychology. The Behavior Analyst, 13, 199-200.

Moss, D.M. \& Keen, E. (1981). The nature of consciousness: The existential-phenomenological approach. En R.S. Valle \& R. von Eckartsberg (Eds.), The metaphors of consciousness (pp.107-119). New York: Plenum Press.

Nye, R.D. (1992). The legacy of B.F. Skinner: Concepts and perspectives, controversies and misunderstandings. Belmont, CA: Wadsworth.

Pérez-Acosta, A.M., Benjumea, S. \& Navarro, J.I. (2001a). Autoconsciencia animal: estudios sobre autodiscriminación condicional en varias especies. Revista Latinoamericana de Psicología, 33, 311-327.

Pérez-Acosta, A.M., Benjumea, S., \& Navarro, J.I. (2001b). Autodiscriminación condicional: la autoconsciencia desde un enfoque conductista. Manuscrito no publicado.

Poling, A., Schlinger, H., Starin, S. \& Blakely, E. (1990). Psychology: A behavioral overview. New York: Plenum Press.

Posner, M.I. \& Raichle, M.E. (1994). Images of mind. New York: Scientific American Library.

Pribram, K.H. (1981). Behaviorism, phenomenology, and holism in psychology. En R.S. Valle \& R. von Eckartsberg (Eds.), The metaphors of consciousness (pp.141-151). New York: Plenum Press.

Rachlin, H. (1991). Introduction to modern behaviorism (3rd ed.). New York: W.H. Freeman.

Rachlin, H. (1994). Behavior and mind: The roots of modern psychology. New York: Oxford University Press.

Revonsuo, A., Kamppinen, M. \& Sajama, S. (1994). General introduction: The riddle of consciousness. En A. Revonsuo \& M. Kamppinen (Eds.), Consciousness in philosophy and cognitive neuroscience. Hillsdale, NJ: Lawrence Erlbaum Associates.

Skinner, B.F. (1974). About behaviorism. New York: Knopf.

Skinner, B.F. (1963). Behaviorism at fifty. Science, 140, 951-958.

Articulo recibido:3-7-2002,

aceptado: 20-10-2003 